Article

\title{
Quantitative Analysis of Weld Pore Size and Depth and Effect on Fatigue Life of Ti-6Al-2Zr-1Mo-1V Alloy Weldments
}

\author{
Weifang Zhang, Xiaopeng Liu ${ }^{(D)}$, Hongxun Wang ${ }^{\mathbb{D}}$, Wei Dai * (D) and Guicui Fu \\ School of Reliability and Systems Engineering, Beihang University, Beijing 100191, China; \\ zhangweifang@buaa.edu.cn (W.Z.); liuxiaopeng@buaa.edu.cn (X.L.); wanghongxun@buaa.edu.cn (H.W.); \\ fuguicui@buaa.edu.cn (G.F.) \\ * Correspondence: dw@buaa.edu.cn; Tel.: +86-10-8233-8673
}

Received: 8 September 2017; Accepted: 5 October 2017; Published: 7 October 2017

\begin{abstract}
Titanium-alloy weldments have been extensively used in engineering structures, and accurate estimation of the fatigue life is beneficial for avoiding catastrophic failures in titanium-alloy structures. The weld pore is a common defect in these weldments that significantly influences the fatigue process. In this study, the weld-pore size and depth and its effect on the fatigue life of Ti-6Al-2Zr-1Mo-1V (TA15) alloy weldments are investigated by adopting fatigue tests and fracture observations. The results show that fatigue crack initiations occurred at the weld pores for all specimens. The diameter and depth of all weld pores on fracture surfaces were then measured, and an indicator, $P$, was proposed, defined as a combination of pore diameter and depth. It was found that all the fatigue cracks initiated from the pore have the smallest $P$ indicator, which suggests that $P$ can be used to judge the location of crack initiation in an individual sample. Moreover, a model was developed based on $P$ to estimate the fatigue life of weldments, considering the effects of weld-pore size and depth. Finally, analogous fatigue tests were carried out for model verification, and results show that the proposed model has a higher accuracy compared with several typical models. The findings of this study can be helpful in estimating the fatigue life and fatigue design of titanium-alloy weldments.
\end{abstract}

Keywords: titanium alloy; GTAW weldments; weld pore; fatigue life

\section{Introduction}

Currently, titanium alloy is widely used in engineering structures because of its properties [1]. Ti-6Al-2Zr-1Mo-1V (TA15) alloy, a kind of $\alpha+\beta$ titanium alloy, has moderate room temperature strength, good thermal stability and excellent weldability, and thus increasingly extensive applications in the aerospace industry, mainly for primary large-scale supporting components [2]. Welding is a common joining method used in these components that has the advantage of being lightweight, while weldments are always fatigue-prone in structures [3,4]. Therefore, the fatigue performance of titanium-alloy weldments significantly affects the structure's durability and reliability [5], and has become a research focus in recent years.

The fatigue behaviors of titanium alloy have been found to be very sensitive to the following two factors: First, the fatigue properties of titanium alloy are closely associated with the microstructure characteristics, such as phase constituent and grain size. The crack nucleation mechanism is related to different mechanical properties between the $\alpha$ phase and $\beta$ phase. The $\alpha$ phase is harder than the $\beta$ phase; thus, elastoplastic behavior incompatibilities at the $\alpha / \beta$ interface results in crack nucleation [6]. Titanium alloy with a fine microstructure, such as an equiaxed structure, exhibits better crack-initiation resistance than a coarse microstructure, such as a lamella structure [7]. However, 
in the crack-propagation stage, the lamellar microstructure exhibits superior crack growth resistance, attributed to a crack path with deflection, bifurcation and secondary cracking [8,9]. Second, titanium alloy is known to have high notch sensitivity [10]. Thus, surface integrity and internal discontinuity of titanium alloy components have become two important concerns for fatigue design engineers. On the one hand, surface integrity, closely associated with the manufacturing processes, can make a substantial difference to fatigue behaviors [11]. Krahmer et al. found that the failure mechanisms are different in materials manufactured by milling and punching, which is related to hardening on the perimeter edges of specimens introduced by manufacturing processes [12]. Besides, surface integrity could also changes with surface-finishing processes. Kim et al. reported that surface microcracks introduced during the shot peening treatment could lead to prior failures near the free surfaces, and the compressive residual stress would prevent further crack growth [13]. On the other hand, internal discontinuities, such as various defects, are one of the non-negligible underlying risks leading to fatigue failures, especially in weldments [14]. Titanium is known to be very reactive towards most atmospheric gases, including oxygen, nitrogen, and hydrogen, at temperatures above $350{ }^{\circ} \mathrm{C}$, especially in the molten state [15]. The oxides of titanium alloy have strong absorption of moisture in the air, which can bring atmospheric gas into a weld pool. Thus, during the welding process any oxides or impurities in the shielding gas or on the material surface, especially the contact surface, would result in the formation of weld pores [16]. Consequently, the weld pore is the most common welding defect in titanium-alloy weldments. Miki et al. [17] listed five types of welding defects that notably influence fatigue life: the weld pore, incomplete penetration, lack of fusion, crack and inclusion. Weld pores are the most likely locations for the initiation of fatigue cracks, and can cause a reduction in fatigue life, expressly in the high-cycle fatigue regime. Obviously, when mechanical engineers design a component, its surface integrity and internal discontinuity should be considered simultaneously [18-20]. This work investigates the effect of weld pores on fatigue life, which is helpful for fatigue design and analysis in titanium-alloy weldments, as well as those metals with pore-like defects.

There are two main methods widely used for estimating the fatigue life of weldments that consider the effects of non-crack-like defects, such as pores and inclusions. One method is based on the equivalent initial crack. The non-crack-like defect is assumed to be an existing equivalent initial crack, and the fatigue life of a welded joint is predominantly controlled by the crack-propagation process. The effect of non-crack-like defects on the fatigue crack growth rate are then investigated and modeled for accurate calculation of the stress intensity factor, which is the key to estimating fatigue crack growth life [21-24]. In this approach, for one type of welded joint the length of equivalent initial crack is defined as an identical value, and individual differences are not reflected. The second method considers the fatigue crack-initiation life, which is added to the fatigue crack growth life as total fatigue life. The effect of weld pores on the fatigue crack-initiation life has been studied $[25,26]$. Unfortunately, the fatigue crack-initiation life, and the large number of material parameters, are difficult to acquire.

Recently, several studies have tried to establish the relationship between total fatigue life and pore parameters, where the pore size and depth are considered as two important parameters [27]. Some researchers ignored changes in pore depth, and developed models with a form of power function to characterize the relationship between fatigue life and pore size [28-30]. In other models, fatigue life was assumed to be solely dependent on the inclusion depth [31,32]. However, the stress condition was not taken into consideration in these studies, which means that model parameters need to be reevaluated under different stress conditions. Shimatani et al. [33] developed a stress-independent model to characterize the relationship between fatigue life, pore size and the stress amplitude at the crack origin. Unfortunately, this model failed to take into account the effects of both size and depth simultaneously. Then, Zhu et al. [34-36] modified this model by introducing pore depth. Nevertheless, the stress amplitude at the crack origin site is often hard to ascertain. Moreover, for specimens with diverse dimensions, pores with the same size and depth would have different influences on the fatigue life, which is also not considered. Quantitative evaluation of the effect of pore size and depth on fatigue life is still an open issue for weldments. Furthermore, existing research merely focuses on the 
effect of the pore where the crack initiates, while there is usually more than one pore in weldments. It is first necessary to determine which pore is the most possible location of crack initiation. At present, few studies have reported on this problem.

In view of the chemical reactivity of titanium alloy, special precautions are required to avoid contamination in the weldments. Accordingly, electron beam welding (EBW) and gas tungsten arc welding (GTAW) are widely accepted methods for titanium alloy weldments, among which GTAW is mostly preferred due to its better economy and comparatively easier applicability [37]. GTAW is performed in an argon gas shield, which can protect the hot metal from gaseous contamination during the welding process; meanwhile, it has excellent control characteristics because of the independent methods used to deliver heat and filler material to the joint.

This study investigates, through a quantitative analysis of weld-pore size and depth, the crack-initiation location and the effect of weld pores on the fatigue life of TA15 alloy weldments made with the GTAW process. The fatigue life of titanium-alloy weldments can be accurately estimated through the proposed method, considering the individual differences introduced by weld pores. Moreover, the findings in this study provide an analysis procedure that can be employed for the selection of welding method before fatigue design. For this paper, fatigue tests and scanning electron microscope (SEM) observations were conducted on TA15 alloy joints welded with GTAW. Then, the experimental results, such as $\mathrm{S}-\mathrm{N}$ curves, fracture analysis and measurements of weld pores, were scheduled. Third, the location of crack initiation and the effects of pores on fatigue life are discussed, and validation of the method is conducted. Finally, conclusions are drawn.

\section{Materials and Methods}

In this work, the experimental material is TA15 titanium alloy, which is manufactured in China. Its main chemical components are shown in Table 1 . The specimens were designed according to GB/T3075-2008, as shown in Figure 1. The titanium-alloy plates were milled, and the roughness of all surfaces were no larger than $3.2 \mu \mathrm{m}$. Before welding, the surfaces of the titanium-alloy plates were cleaned using acetone to protect weld zones from oil, moisture, dirt and other impurities. Then, the titanium-alloy plates were butt-welded along the longitudinal direction, and a shielding gas of argon was continually provided during the molten pool welding solidification process to prevent the generation of weld pores. After welding, vacuum annealing (holding $120-180 \mathrm{~min}$ at $600{ }^{\circ} \mathrm{C}$ and then being cooled inside the furnace to room temperature) was performed on titanium-alloy plates to remove residual stresses and stabilize the microstructure. The fatigue specimens were machined from the gas tungsten arc-welded sheets.
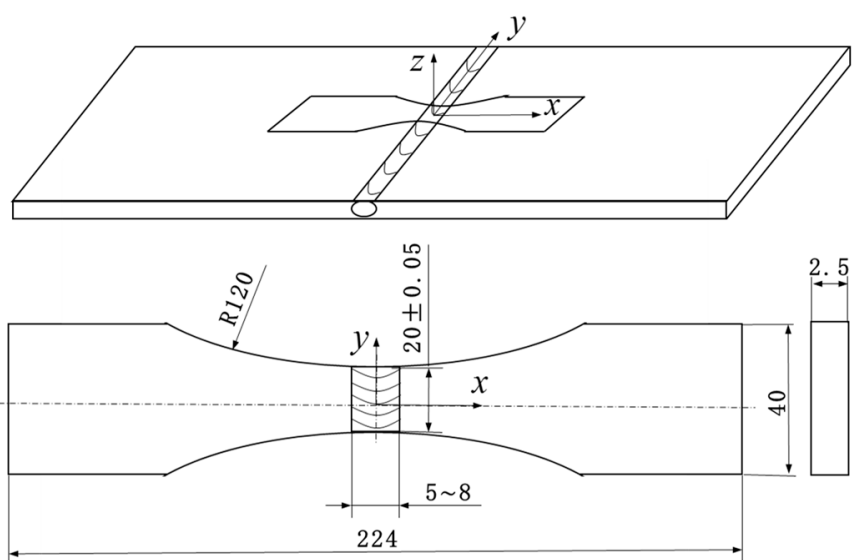

Figure 1. Specimens of fatigue tests (dimensions in $\mathrm{mm}$ ). 
Table 1. Chemical composition of TA15 titanium alloy wt \%.

\begin{tabular}{ccccccc}
\hline Al & $\mathbf{Z r}$ & $\mathbf{M o}$ & $\mathbf{V}$ & $\mathbf{O}$ & $\mathbf{N}$ & $\mathbf{T i}$ \\
\hline 6.3 & 1.97 & 1.4 & 1.4 & 0.08 & 0.01 & Other \\
\hline
\end{tabular}

The optical micrographs (OLYMPUS PME3, Beijing, China) of different welded regions, etched by $5 \mathrm{vol} \% \mathrm{HF}$ and $12 \mathrm{vol} \% \mathrm{HNO}_{3}$ in water, are shown in Figure 2. The base metal (BM) microstructure is an equiaxed $\alpha+\beta$ structure. The weld zone (WZ) microstructure is a Widmanstädter structure with serrate and thick acicular $\alpha$, which can be attributed to the high heat input and fast cooling during the GTAW process. The heat-affected zone (HAZ) near the WZ consists of a slender lamellar Widmanstädter structure, while the HAZ near the BM consists of the equiaxed $\alpha$ and massive $\alpha$, which shows a gradual change from $\mathrm{WZ}$ to $\mathrm{BM}$ due to the temperature gradients.

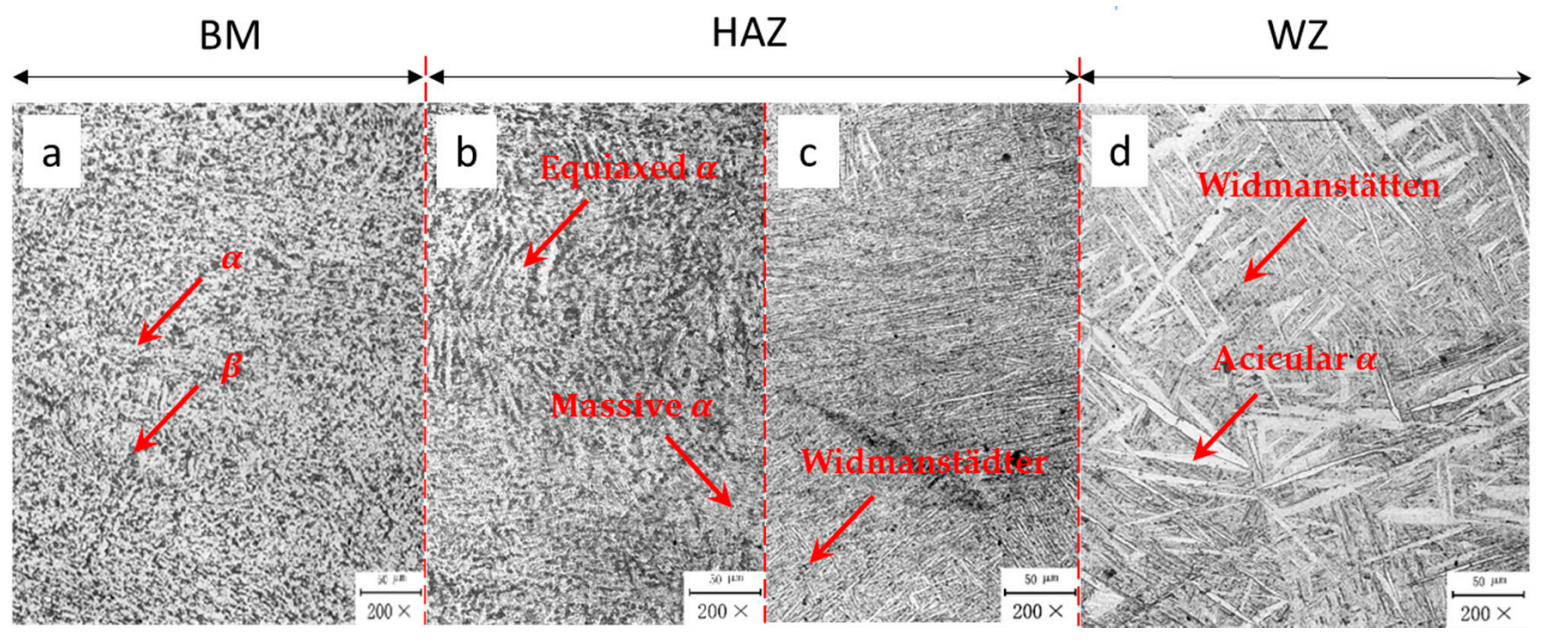

Figure 2. Optical micrographs of different weld metal regions of the specimens: (a) base metal (BM);

(b) heat-affected zone (HAZ) near the BM; (c) HAZ near the weld zone (WZ); (d) WZ.

Tensile tests (INSTRON4507, Beijing, China) were performed at room temperature for three specimens of TA15 alloy and its GTAW joint, respectively, according to ASTM E8/E8M at the strain rate of $10^{-1} \mathrm{~s}^{-1}$, and the mechanical properties are listed in Table 2. Compared with TA15, the tensile strength of the GTAW joint was essentially unchanged, while its elongation decreased sharply. Moreover, Vickers microhardness tests were executed for three welded specimens, using a computerized Buehler hardness tester with a loading of $500 \mathrm{~g}$ and a dwell time of $15 \mathrm{~s}$, and the microhardness values are shown in Figure 3. Note that for each location on the $X$-axis away from welded center, there are three test points on the $Y$-axis, and the microhardness of each location is equal to the mean value of them, as shown in Figure 3.

The fatigue tests performed in this work can be seen in Table 3. Fatigue tests were conducted on an ultrasonic fatigue testing equipment of AMSLER under constant amplitude axial-loading at room temperature, and the fatigue loadings were in a form of sine curves. After testing, the fracture surfaces of Groups A and B specimens (marked in Table 3), numbered A1-A5 and B1-B5, respectively, were examined through SEM (scanning electron microscope) to investigate the effect of weld pores. As for the rest of the specimens, they were employed for fitting S-N curves and the SEM observations were not performed on them. 
Table 2. Room-temperature mechanical properties of TA15 and its GTAW (gas tungsten arc welding) joint.

\begin{tabular}{ccc}
\hline Material & Tensile Strength (MPa) & Elongation (\%) \\
\hline Base metal & 1018.8 & 15.3 \\
GTAW joint & 979.0 & 5.5 \\
\hline
\end{tabular}

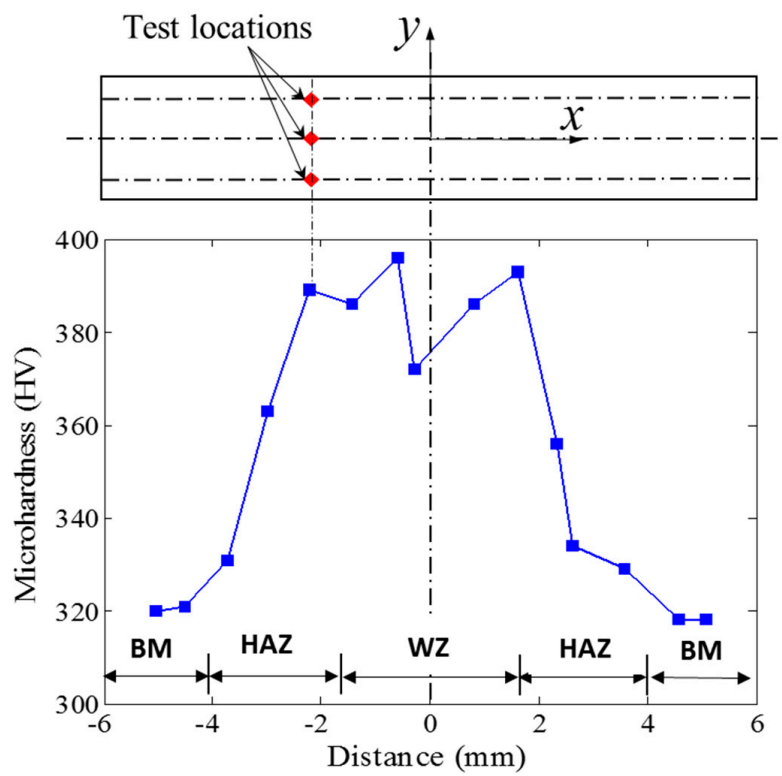

Figure 3. Vickers microhardness of specimens.

Table 3. Stress conditions of two groups of specimens for SEM (scanning electron microscope) observation.

\begin{tabular}{|c|c|c|c|}
\hline Frequency & $\begin{array}{l}\text { Stress Ratio } \\
S_{\min } / S_{\max }\end{array}$ & $\begin{array}{l}\text { Stress Amplitude } \\
\left(S_{\max }-S_{\min }\right) / 2\end{array}$ & Number of Samples \\
\hline \multirow{7}{*}{$70 \mathrm{~Hz}$} & \multirow{7}{*}{0.06} & $370 \mathrm{MPa}$ & 2 \\
\hline & & $325 \mathrm{MPa}$ & 2 \\
\hline & & $282 \mathrm{Mpa} \mathrm{(Group} \mathrm{A)}$ & 5 \\
\hline & & $260 \mathrm{MPa}$ & 3 \\
\hline & & $245 \mathrm{MPa}$ & 2 \\
\hline & & $238 \mathrm{MPa}$ & 2 \\
\hline & & $230 \mathrm{MPa}$ & 1 \\
\hline \multirow{7}{*}{$70 \mathrm{~Hz}$} & \multirow{7}{*}{-1} & $500 \mathrm{MPa}($ Group B) & 5 \\
\hline & & $450 \mathrm{MPa}$ & 2 \\
\hline & & $400 \mathrm{MPa}$ & 2 \\
\hline & & $360 \mathrm{MPa}$ & 2 \\
\hline & & $345 \mathrm{MPa}$ & 3 \\
\hline & & $330 \mathrm{MPa}$ & 2 \\
\hline & & $320 \mathrm{MPa}$ & 1 \\
\hline
\end{tabular}

\section{Results}

\subsection{S-N Curves and Scatter of Fatigue Life}

Relationships between the stress amplitude and the fatigue life of all the specimens are shown in Figure 4. Each symbol represents the result of one test sample. The sample was regarded as a runout if it did not fail within $10^{7}$ cycles. The fatigue life of samples of Groups A and B has been marked in Figure 4. The mean S-N curve was fitted by the experimental data based on the three-parameter S-N model proposed by Weibull: 


$$
N_{p}=S_{f}^{\prime}\left(S_{a}-S_{a c}\right)^{b}
$$

where $S_{a c}$ is the fatigue limit, and $S_{f}^{\prime}$ and $b$ are constants related to the materials. The parameters of mean S-N curves are shown in Table 4. As seen from Figure 4, fatigue life is different under the same stress condition, which reveals a large scatter. This is due to the effects of various uncertainties such as loading, environment, defects, material, etc. For welded joints of titanium alloy, the most important effect factor would be the weld pores.

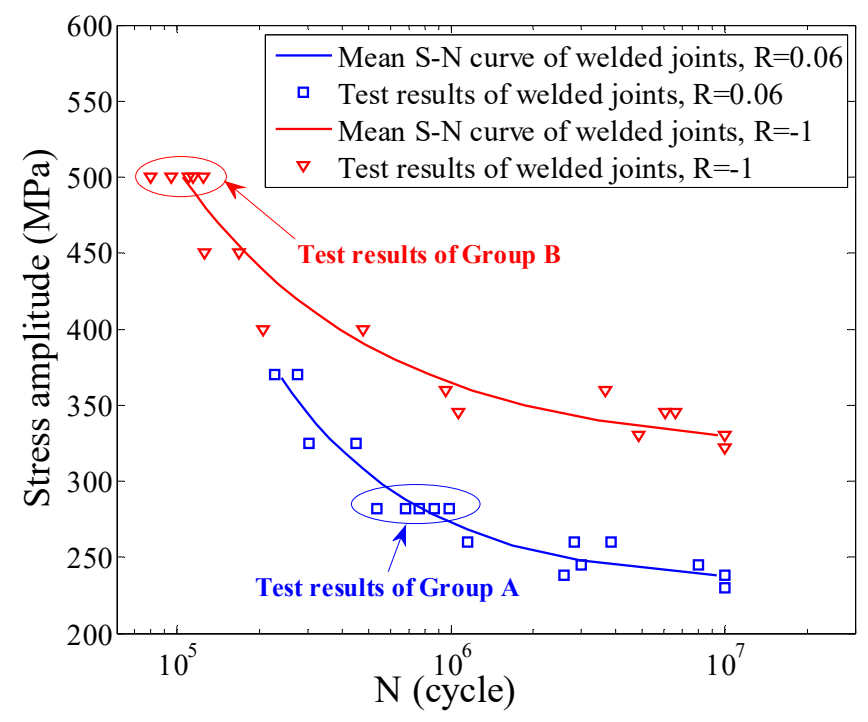

Figure 4. Fatigue life (S-N curves) of specimens.

Table 4. Parameters of mean S-N curves.

\begin{tabular}{cccc}
\hline Stress Ratio & $S_{f}^{\prime} / \times \mathbf{1 0}^{\mathbf{7}}$ & $\boldsymbol{b}$ & $S_{a c}$ \\
\hline 0.06 & 7.7148 & -1.1747 & 238 \\
-1 & 58.2091 & -1.6569 & 330 \\
\hline
\end{tabular}

\subsection{Fracture Analysis}

According to the SEM observations of fracture surfaces, all the specimens of Groups A and B had weld pores, which indicates that weld pores are prevalent in TA15-alloy GTAW joints. In addition, it was found that all the fractures originated from weld pores, which suggests that the fatigue crack tends to initiate from weld pores. These results are consistent with those in previous studies [38,39]. Representative fracture morphologies of the crack initiations are shown in Figure 5. From the fracture morphologies of Group A (Figure 5a,b), it can be seen that the crack initiates from the pore and propagates around it, and a few secondary cracks are found around the edge of the crack-initiation pore. Figure $5 c$,d shows the fracture morphologies of Group B. Compared with that of Group A, the crack-initiation region is smoother, and friction traces can be easily observed, which are caused by the crack closure behaviors under the negative stress ratio. Besides, there are more secondary cracks around the crack-initiation pore, due to the higher stress amplitude. Figure 5e,f gives two typical fracture morphologies containing pores with different locations. In practice, there are always multiple pores in welded joints, while only one of them would be the primary crack initiation and cause the final fracture; the rest of them would be located in the propagation or final fracture regions. In Figure 5e, the crack initiates from pore A and then propagates through pore B to the right. In Figure $5 f$, the crack initiates from pore $C$ and there is a pore $D$ located in the final fracture region. In addition, it is worth noting that the crack initiations would also occur from other sites, for example the left surface edge in 
Figure 5e, which are likely caused by cyclic slip; even so, they contribute little to the propagation of the primary crack and final fracture.

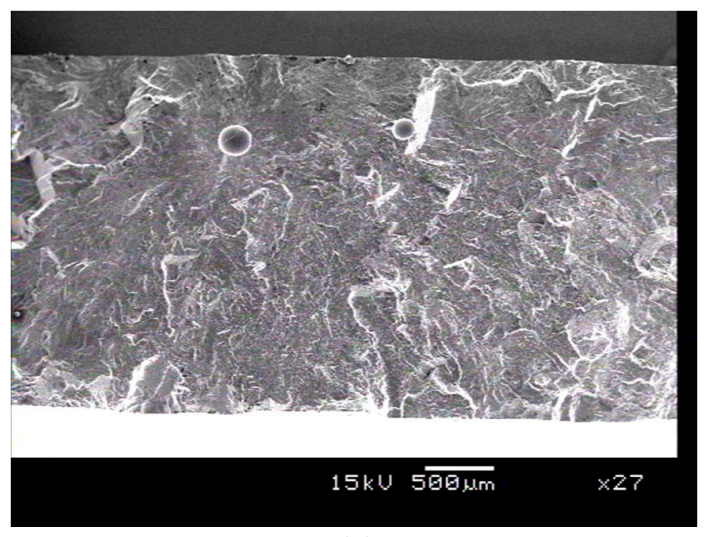

(a)

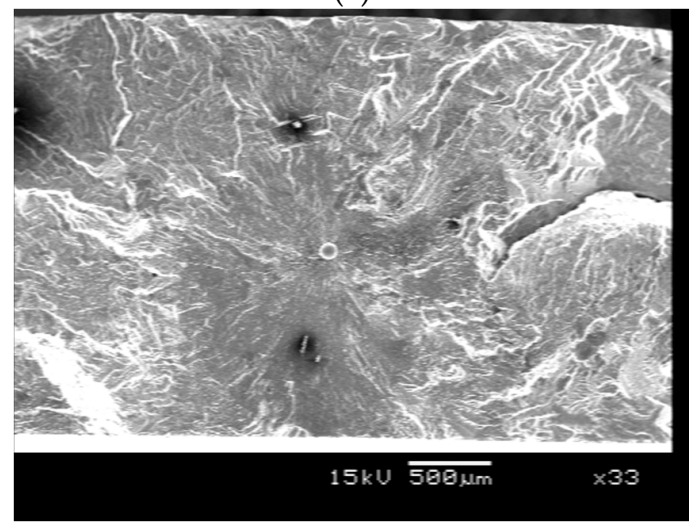

(c)

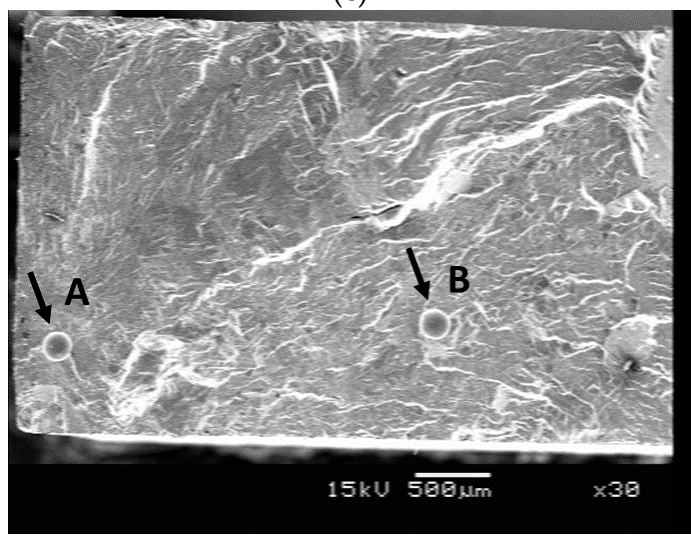

(e)

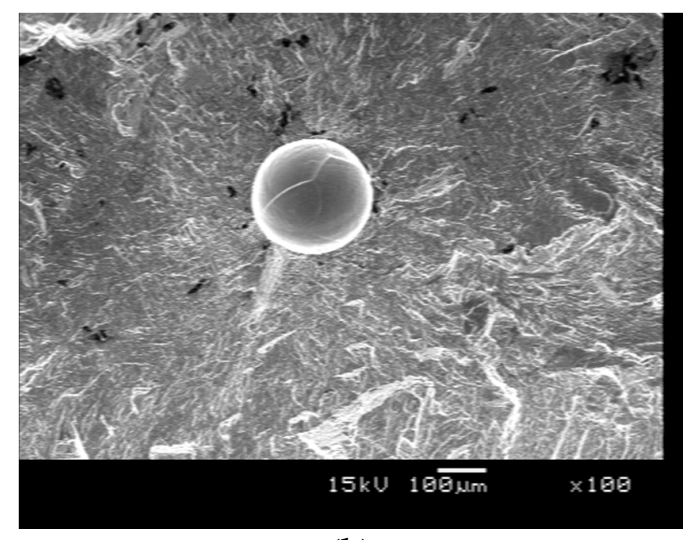

(b)

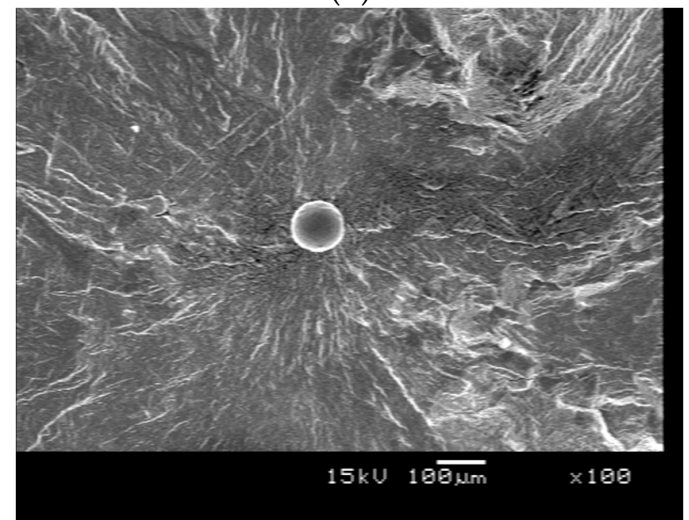

(d)

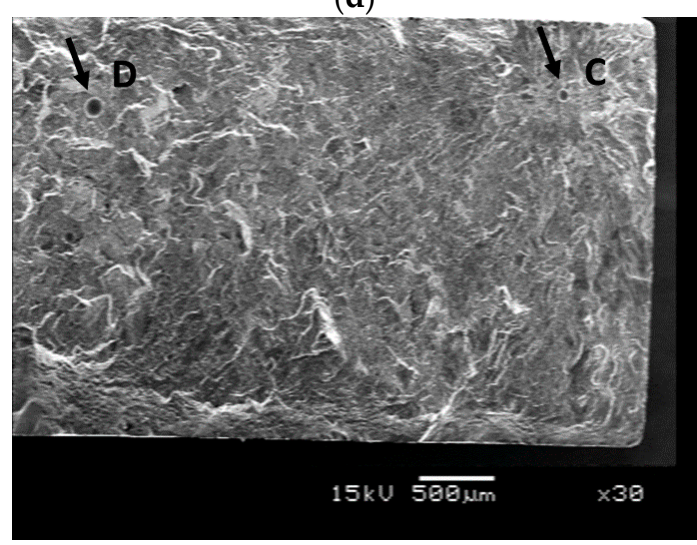

(f)

Figure 5. Typical SEM images: a crack initiation of a Group A specimen in (a) low-magnification and (b) high-magnification; a crack initiation of a Group B specimen in (c) low-magnification and (d) high-magnification; (e) a pore (arrows B) at a propagating region in a Group B specimen; (f) a pore (arrows D) at a final fracture region in a Group A specimen.

\subsection{Measurements of Pore Diameter and Depth}

In this study, the weld pores are spherical and can be regarded as non-crack-like defects. Murakami et al. [40] proposed a commonly accepted parameter, $\sqrt{\text { area }}$, standing for the projected area 
of defects, to characterize the size of non-crack-like defects. The relationship between parameter $\sqrt{\text { area }}$ and pore diameter is as follows:

$$
d=2 \sqrt{\frac{\text { area }}{\pi}}
$$

where $d$ is the pore diameter. Therefore, parameter $\sqrt{\text { area }}$ can be simplified as the pore diameter.

Diameters and depths of all pores on fracture surfaces were measured according to the SEM images. A schematic of the measurements of pore diameter and depth on the fracture surface is shown in Figure 6,where $d$ is the pore diameter, $h$ is the nearest distance between pore center and specimen surface, and $t$ is the specimen thickness perpendicular to the direction of principal stresses. Hence, the value of $d$ and $h$ are in the range of $0-t$ and $0.5 d-0.5 t$, respectively.

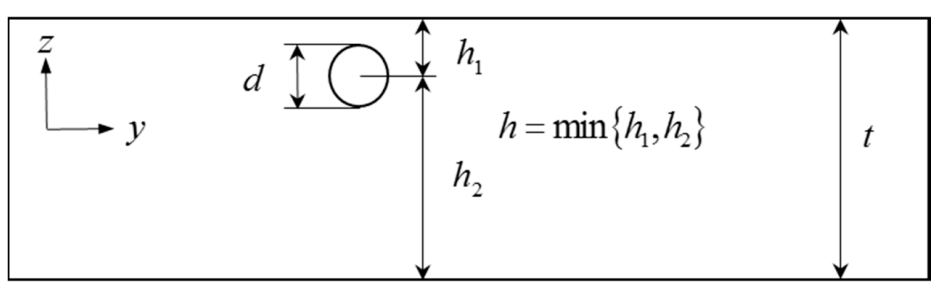

Figure 6. Schematic of the measurements of pore diameter and depth $(\mathrm{mm})$.

For the purpose of normalization, the relative diameter $D$ and relative depth $H$ are defined as follows:

$$
\begin{gathered}
D=\frac{d}{t} \\
H=\frac{2 h-d}{t-d}
\end{gathered}
$$

Apparently, $0<D<1.0,0<H<1.0$, according to the range of $d$ and $h$. When $H$ approaches to 0 , the pore has a tendency to become a surface pore. When $H$ equals to 1 , the pore is located at the center of the section.

Figure 7 shows the relationship between relative diameter and relative depth of all the observed pores. Each line represents a sample, and each marker on the line represents a pore on the fracture surface of the same sample. The solid marker denotes the critical pore, which is defined as the pore leading to the crack initiation and sample failure. The hollow marker denotes the pore in other regions.

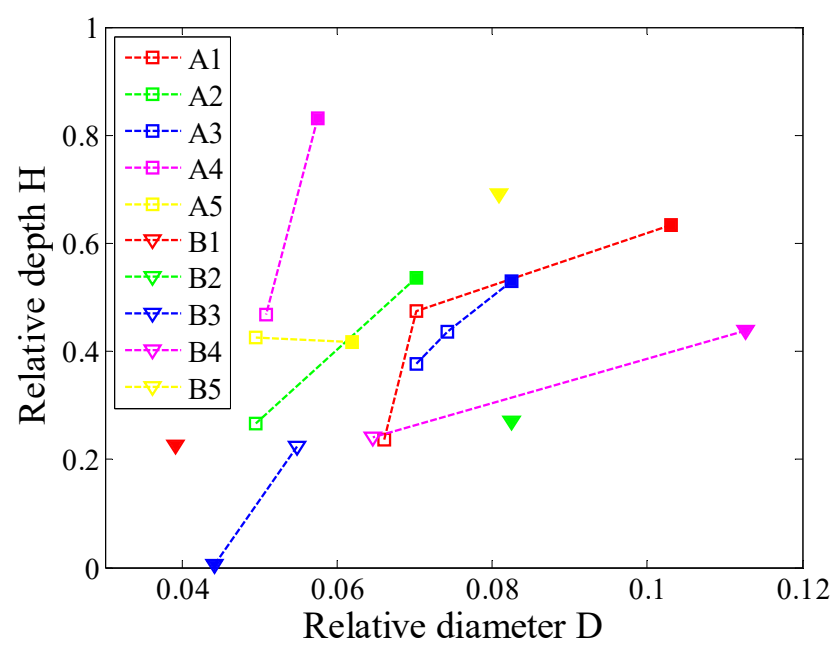

Figure 7. Relationships between relative diameter and relative depth of pores in specimens of Groups A and B. 


\section{Discussion}

\subsection{Location of Crack Initiation}

For all specimens in this study, fatigue cracks initiated solely from weld pores. This is due to the following two reasons: First, the geometrical discontinuity caused by weld pores produces severe stress concentration around them, and results in a priority of crack initiation from weld pores. Second, weld pores are mainly located at the WZ where the crack initiation more likely occurs [23]. On the one hand, it can be seen from Figure 3 that the microhardness of WZ is higher than that of HAZ and $\mathrm{BM}$, which means that there are higher strength and lower plasticity at the WZ. As a consequence, WZ metal is more sensitive to defects, and crack initiation easily occurs at this region. On the other hand, the coarse microstructures in WZ (see in Figure 2) impedes the slip transfer, making it easier for dislocations to pile up at the boundary of $\alpha / \beta$, which cause a lower crack-initiation resistance in WZ [8].

Generally, there is more than one pore in welded joints, but only one of them will result in crack initiation and final fracture. This section will discuss which pore becomes the crack initiation. Crack initiation is mainly affected by the stress-concentration and physical properties around pores. The physical properties around pores are identical in one specimen. Hence, the location of the crack initiation is dependent on the stress concentration around the pores. Stress concentration can be characterized by the stress-concentration factor, which is defined as the ratio of peak stress at notch root to nominal stress. The pore with the larger stress-concentration factor tends to initiate the crack more easily. The stress-concentration factor around a pore is determined by the pore diameter and depth. Zhao et al. [19] have stated that a pore with larger diameter and smaller depth has a larger stress-concentration factor. However, in this work, the pore with a larger relative diameter always had a larger relative depth for almost all samples (see Figure 7). That is, a larger diameter and smaller depth cannot be achieved simultaneously. In this case, except for sample B3, the pore where the crack initiated is that with the largest relative diameter. For B3, the pore where the crack initiated is that with the smallest relative depth. Obviously, there is a competitive relationship between larger relative diameter and smaller relative depth.

In order to analyze the combined effect of pore diameter and depth on stress concentration in detail, a series of finite element simulations based on ANSYS were employed. 2-D finite element models containing pores with different diameters and depths were established, according to the actual size of specimens. Geometrical features of 2-D finite element models are similar to each other. Hence, only one example is presented here, as shown in Figure 8. The material matrix is modeled to be elastic. The model is meshed by 2335 4-node quadrilateral elements.

Results of simulations are shown in Figure 9. Figure 9a shows the variation of stress-concentration factors with different relative depths. It is observed that stress-concentration factors decease rapidly with the increase of relative depth when relative depth is small. However, when relative depth becomes larger, stress-concentration factors tend to decrease at a slow rate, which indicates that relative depth has little impact on the stress-concentration factor in this case. Figure $9 \mathrm{~b}$ shows the variation of stress-concentration factors with different relative diameters. Stress-concentration factors are essentially constant with the increase of relative diameter when relative diameter is small. However, when relative diameter becomes larger, the stress-concentration factor starts to increase at a high rate, which indicates that the stress-concentration factor is significantly influenced by relative diameter in this case. In this work, the relative depths of most pores were larger than 0.2 (see in Figure 7), where the stress-concentration factor is governed by the relative diameter. Therefore, the crack initiated at the pore with the largest relative diameter. However, for sample B3, the relative depths of pores are small, where the relative depth has a significant influence on the stress-concentration factors. Thus, the crack initiated at the pore with the largest relative depth. 

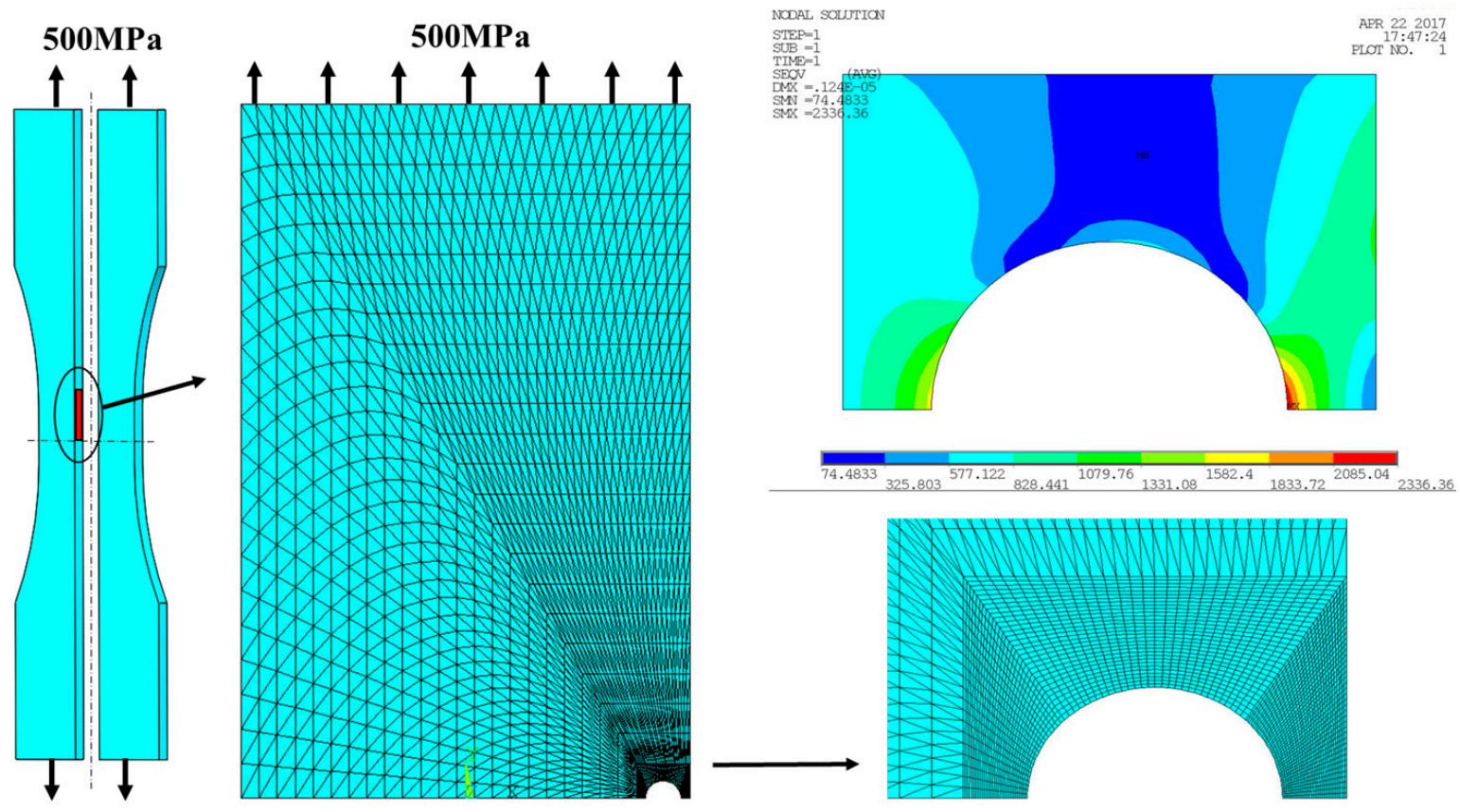

Figure 8. An example of the finite element model and stress distribution of a fatigue specimen.

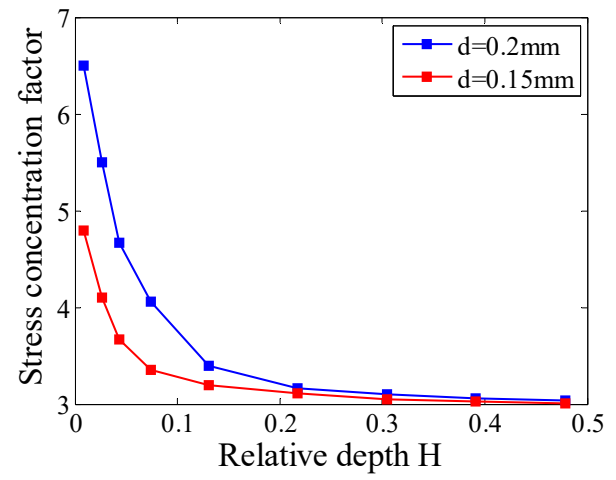

(a)

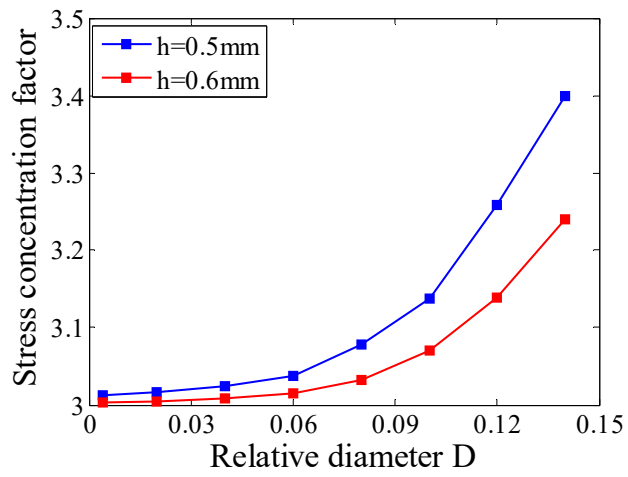

(b)

Figure 9. (a) Variation of the stress-concentration factor with the increase of relative depth where the pore diameter is equal to $0.2 \mathrm{~mm}$ and $0.15 \mathrm{~mm}$; (b) variation of the stress-concentration factor with the increase of relative depth where the pore depth is equal to $0.5 \mathrm{~mm}$ and $0.6 \mathrm{~mm}$.

To characterize the combined effect of pore diameter and depth on stress concentration and crack initiation, an indicator needs to be defined. The changes of stress-concentration factor with relative depth in Figure 9 a can be represented by the function $1 / \sqrt{H}$, and that in Figure $9 \mathrm{~b}$ can be represented by the function $D^{3}$. Therefore, an indicator $P$ can be expressed as follows:

$$
P=\frac{\sqrt{H}}{D^{3}}
$$

Figure 10 shows the indicator $P$ of pores in samples with multi-pores on the fracture surfaces. Each line represents a sample and each marker on the line represents a pore in the fracture surface of this sample. The solid markers denote the critical pores, and the hollow markers denote the pores in other regions. It can be seen that the crack initiated from the pore with the smallest indicator $P$ for all samples, which shows that $P$ can be regarded as an indicator to judge the crack initiation. That is, in an individual specimen, the pore with the smallest $P$ would be the most likely location of the crack 
initiation. In this study, we provided an expression (Equation (5)) of $P$ based on the finite element analysis. The expression has been accessed by the pore data in this study, and the results show that it satisfied the data well. Nevertheless, it needs to be noted that pores in this study solely refer to the pores observed on the fracture surface, and an individual specimen generally contains many other pores. Similar work would be encouraged to obtain all pores' geometrical characteristics by non-destructive techniques in order to find a more suitable expression of $P$, if the detection threshold and measurement accuracy can reach a high level.

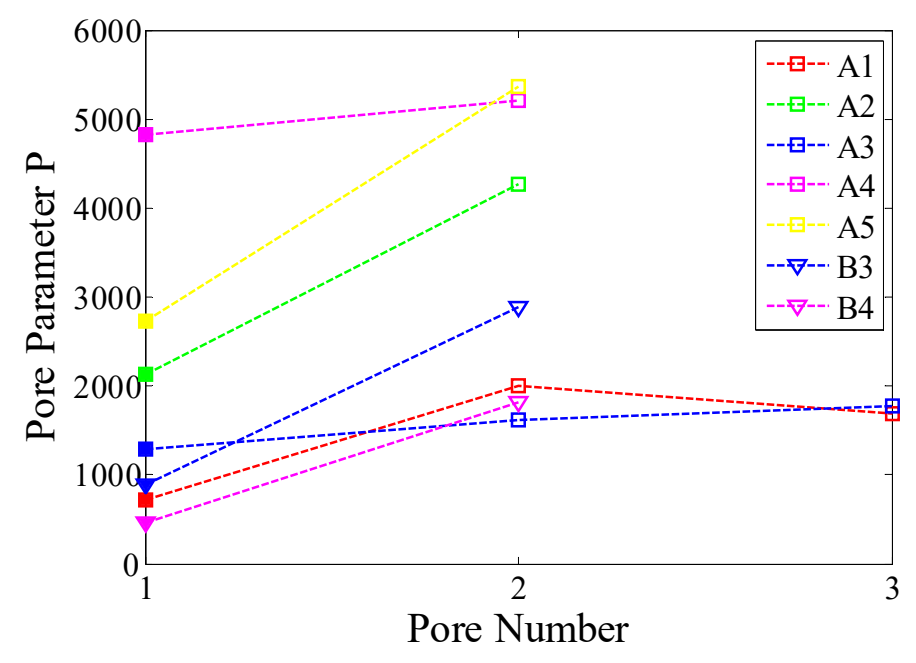

Figure 10. Indicator $P$ of all pores in specimens of Groups A and B.

\subsection{The Effect of Pore Diameter and Depth on Fatigue Life}

It has been revealed that weld defects in propagation and fracture regions have little influence on fatigue life [33]. Therefore, only the effect of the critical pore will be discussed in this section. Generally, fatigue life varies under the same stress condition due to the effects of uncertainties, such as loading, environment, defects, material, etc. For titanium alloy-welded joints, the most important factor influencing the scatter of fatigue life is considered to be the weld pores [40]. Therefore, the deviation between the actual fatigue life and mean fatigue life can be considered a good indicator for characterizing the effect of critical pores on fatigue life. However, it can be observed from Figure 4 that the scatter of fatigue life under different stress conditions is different. The scatter of fatigue life is larger under smaller stress conditions. The reason is that when under a smaller stress condition, the effect of stress becomes weaker and the effect of various uncertainties, particularly weld pores, becomes more significant. To eliminate the effect of stress condition on fatigue life scatter, an indicator $F$ is defined as the relative deviation between the actual fatigue life and mean fatigue life:

$$
F=\frac{N_{f}-N_{p}}{N_{p}}
$$

where $N_{f}$ is the actual fatigue life of specimens, and $N_{p}$ is the mean fatigue life calculated by an arbitrary S-N model under a corresponding stress condition. In this work, the three-parameter S-N model proposed by Weibull was taken as an example (see Equation (1)). Obviously, a larger value of $F$ means a longer lifetime of the specimen.

Fatigue life is strongly influenced by the stress concentration around the critical pore, which can be characterized by the indicator $P$. Figure 11 shows the relationship between the indicator $P$ of critical pores and indicator $F$. It can be seen that there is a linear relation in the semi-logarithm coordinate 
between them. The line in Figure 11 is the fitting curve using a linear regression method, and the regression model is obtained as follows:

$$
F=m \ln P+C
$$

where $m=0.166$, and $C=-1.234$. A common indicator for evaluating the goodness of fitting is the coefficient of determination $R^{2}$. This describes how well the regression model represents a set of real observations, which ranges from 0 to 1 . Perfect regression occurs when $R^{2}=1$, which means that the dependent variable is entirely determined by the independent variables involved in the regression model. The $R^{2}$ here is equal to 0.628 , which indicates that the $\ln P$ can explain $62.8 \%$ of the information of indicator $F$. It means that the scatter of fatigue life of welded joints is mainly caused by the weld pores. The remaining $37.2 \%$ of the information of indicator $F$ can be interpreted by other factors, which means that the scatter of fatigue life is also caused by other uncertainties, such as material organization, stress, experimental environment, etc.

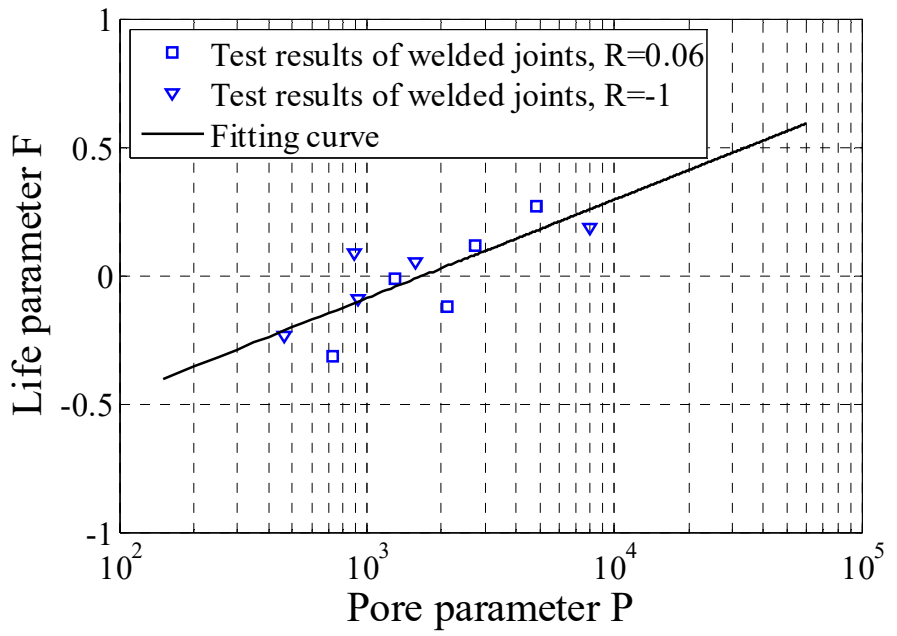

Figure 11. The relationship between life indicator $F$ and pore indicator $P$.

Bringing Equations (6) and (7) into Equation (8), a model for fatigue life estimation of welded joints considering the effect of pores is obtained as follows:

$$
N_{f}=N_{p}\left[m \ln \frac{\sqrt{H}}{D^{3}}+C+1\right]
$$

where $m$ and $C$ are constants related to the base metal material and welding method. The values of $m$ and $C$ can be fitted by experimental data.

\subsection{Method of Validation}

This study provides a method to estimate the fatigue life of titanium-alloy weldments. Non-destructive inspection can be used to obtain the diameter and depth of all pores in an individual weldment. The pore with the smallest indicator $P$ would be the most possible location of crack initiation, i.e., the critical pore. According to the indicator $P$ of the critical pore and the stress condition, fatigue life can be estimated in advance based on Equation (9). In order to validate the performance of the method proposed in this study, analogous fatigue tests were carried out under the stress amplitude of $282 \mathrm{MPa}$ with a stress ratio of 0.06 . For each specimen, cycles to the final failure were recorded, and the depth and diameter of pores on the fracture surface were measured according to the SEM images. The tests and calculated results are shown in Table 5. The pores with the marker ${ }^{*}$ represent the critical pores. 
Table 5. Results of verification tests.

\begin{tabular}{ccccccc}
\hline $\begin{array}{c}\text { Specimen } \\
\text { Number }\end{array}$ & $\begin{array}{c}\text { Pore } \\
\text { Number }\end{array}$ & $\begin{array}{c}\text { Pore Diameter } \\
(\mathbf{m m})\end{array}$ & $\begin{array}{c}\text { Pore Depth } \\
(\mathbf{m m})\end{array}$ & $\begin{array}{c}\text { Actual Fatigue Life } \\
\text { (Cycle) }\end{array}$ & $\begin{array}{c}\text { Indicator } \\
\boldsymbol{P}\end{array}$ & $\begin{array}{c}\text { Calculated Fatigue } \\
\text { Life (Cycle) }\end{array}$ \\
\hline \multirow{2}{*}{ V1 } & P11 & $0.2674^{*}$ & $0.6210^{*}$ & & 539.9 & \\
& P12 & 0.1205 & 0.3231 & $5.412 \times 10^{5}$ & 4197.4 & $6.312 \times 10^{5}$ \\
& P13 & 0.1122 & 0.3891 & & 5842.2 & \\
V2 & P21 & 0.1607 & 0.4770 & & & \\
& P22 & $0.1514^{*}$ & $0.2514^{*}$ & $8.154 \times 10^{5}$ & 2192.5 & $7.826 \times 10^{5}$ \\
\hline
\end{tabular}

It can be seen from Table 5 that the fatigue cracks both initiated from the pores (P11 and P22) with the smallest indicator $P$ for the two specimens, which is consistent with the conclusion in Section 4.1. Moreover, the fatigue life calculated by Equation (8) is close to the actual fatigue life. In order to further validate the proposed model, the fatigue life calculated by Equation (8) was compared with the results calculated by several similar models, including the model in [23] (Equation (2)), the model in [26] (Equation (5)), and Equation 1 (three-parameter S-N model), respectively. The formula of the model proposed in [23] is as follows:

$$
N_{f}=C_{2}(\text { area })^{m_{2}}
$$

where area is the area of critical pore, $C_{2}$ and $m_{2}$ are constants related to the base material, welding method and stress condition which were fitted by the experimental data of Group A. Here $C=4.524 \times 10^{4}, m=-0.7402$. The formula of the model in [26] is as follows:

$$
\left\{\sigma_{a}(\text { area })^{1 / 12} D^{\beta}\right\}^{\alpha} N_{f}=C_{3}
$$

where $\sigma_{a}$ is stress amplitude, $D$ is a depth-related parameter of the pore, and $\alpha, \beta$ and $C_{3}$ are constants related to the base material which were fitted by the experimental data. Here $\alpha=2.89, \beta=-0.21$, $\mathrm{C}=1.823 \times 10^{12}$.

Comparisons of actual results and the calculations by Equation (8) (M1), the model in [23] (M2), the model in [26] (M3), and Equation (1) (M4), are shown in Figure 12. Figure 12a shows the fatigue life results of the samples V1 and V2, respectively, and Figure 12b shows the average relative errors between actual fatigue life and calculated fatigue life. It can be seen that the fatigue life calculated by M1 is closest to actual fatigue life, and has the smallest average relative error compared with other models. The observations of Figure 12 indicate that the model proposed in this study has a higher estimation accuracy of fatigue life.

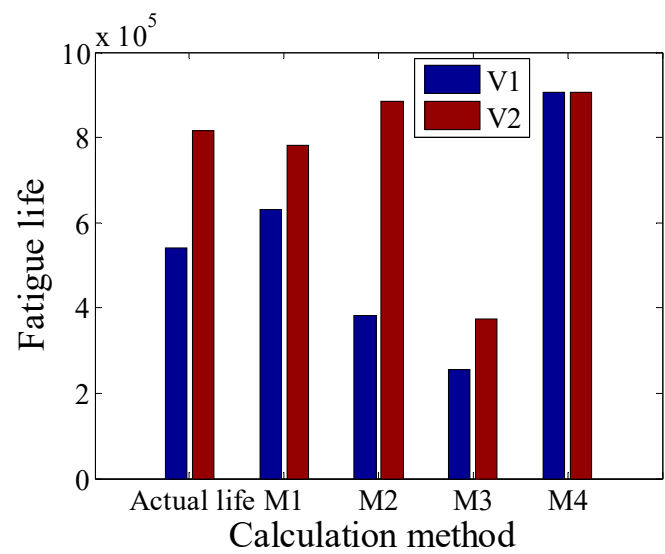

(a)

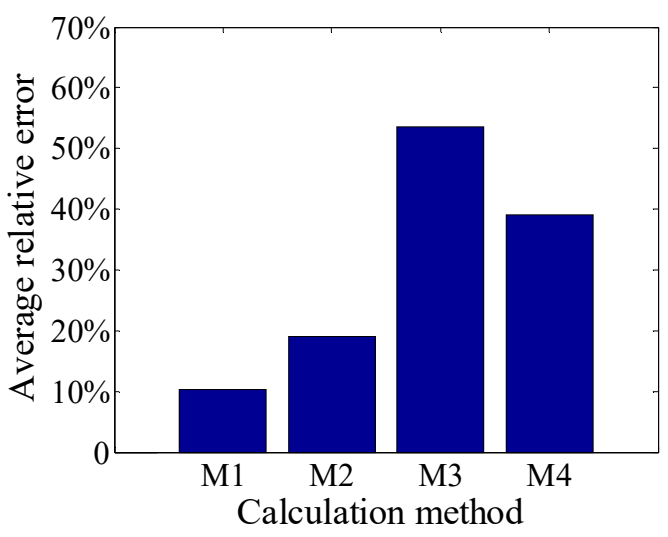

(b)

Figure 12. Comparison of actual results and calculated results by the model in this study (M1), the model in [23] (M2), the model in [26] (M3), and the S-N model (M4): (a) fatigue life; (b) relative error. 


\section{Conclusions}

In this study, the location of crack initiation was analyzed through quantitative analysis of pore size and depth. Additionally, the effect of pore size and depth on the fatigue life of welded joints of TA15 titanium alloy was investigated. The main conclusions obtained in this work are summarized as follows:

(1) For all specimens, fatigue crack initiations occurred at the weld pores.

(2) An indicator $P$ was proposed to combine the effect of pore diameter and depth. An expression (Equation (5)) of $P$ was provided based on the finite element analysis, and it has been accessed by the measurements of diameter and depth of pores on fracture surfaces in this study. Results showed that all the fatigue cracks initiated from the pore with the smallest $P$, which suggests that $P$ can be used to judge the critical pore.

(3) A model based on S-N curve and indicator $P$ was established to evaluate quantitatively the effect of pore size and depth on fatigue life, and it can be applied under arbitrary stress conditions and specimen thicknesses. The indicator $P$ could explain $62.8 \%$ of the information of indicator $F$, which means that the scatter of fatigue life of welded joints is mainly caused by the weld pores.

(4) The model was validated through analogous fatigue tests. The results showed that the indicator $P$ successfully judged the critical pore, and the calculated fatigue life were well consistent with the actual fatigue life. Moreover, the proposed model has been proved to have a higher accuracy for fatigue life estimation in comparison with several typical models.

Acknowledgments: This work was supported by the Technical Foundation Program (grant JSZL 2014601 B001) of the Ministry of Industry and Information Technology of China.

Author Contributions: Weifang Zhang and Xiaopeng Liu conceived and designed the experiments; Weifang Zhang, Hongxun Wang and Xiaopeng Liu performed the experiments; Weifang Zhang, Hongxun Wang and Xiaopeng Liu analyzed the data; and Wei Dai, Xiaopeng Liu and Guicui Fu contributed to the writing and editing of the manuscript.

Conflicts of Interest: The authors declare no conflict of interest.

\section{References}

1. Ji, Y.P.; Wu, S.J.; Zhao, D.L. Microstructure and mechanical properties of friction welding joints with dissimilar titanium alloys. Metals 2016, 6, 108. [CrossRef]

2. Sun, Z.C.; Yang, H. Microstructure and mechanical properties of TA15 titanium alloy under multi-step local loading forming. Mat. Sci. Eng. A Struct. 2009, 523, 184-192. [CrossRef]

3. Wang, S.Q.; Li, W.Y.; Zhou, Y.; Li, X.; Chen, D.L. Tensile and fatigue behavior of electron beam welded dissimilar joints of Ti-6Al-4V and IMI834 titanium alloys. Mater. Sci. Eng. A 2016, 649, 146-152. [CrossRef]

4. Taheri, F.; Lu, Y.; Mehrzadi, M. Microstructure and fatigue characteristic of AM60B magnesium alloy. Metals 2012, 2, 411-440. [CrossRef]

5. Özdeş, H.; Tiryakioğlu, M. On the relationship between structural quality index and fatigue life distributions in aluminum aerospace castings. Metals 2016, 6, 81. [CrossRef]

6. Yang, L.; Wang, B.Y.; Lin, J.G.; Zhao, H.J.; Ma, W.Y. Ductile fracture behavior of TA15 titanium alloy at elevated temperatures. Int. J. Miner. Metal. Mater. 2015, 22, 1082-1091. [CrossRef]

7. Yu, Y.; Ye, W.; Hui, S.; Xiong, B.; Li, S. Comparison of the fatigue and fracture of Ti-6Al-2Zr-1Mo-1V with lamellar and bimodal microstructures. Mat. Sci. Eng. A Struct. 2007, 460, 140-145. [CrossRef]

8. Yang, W.; Zhang, S.Q.; Tian, X.J.; Wang, H.M. High-cycle fatigue crack initiation and propagation in laser melting deposited TC18 titanium alloy. Int. J. Miner. Metal. Mater. 2013, 20, 665-670. [CrossRef]

9. Li, S.; Xiong, B.Q.; Hui, S.X.; Ye, W.J.; Yu, Y. Effects of microstructure on fatigue crack growth behavior of Ti-6Al-2Zr-1Mo-1V ELI alloy. Mater. Charact. 2008, 59, 397-401. [CrossRef]

10. Long, M.; Rank, H.J. Titanium alloys in total joint replacement-A materials science perspective. Biomaterials 1998, 19, 1621-1639. [CrossRef]

11. Novovic, D.; Dewes, R.C.; Aspinwalla, D.K.; Voiceb, W.; Bowena, P. The effect of machined topography and integrity on fatigue life. Int. J. Mach. Tool. Manuf. 2004, 44, 125-134. [CrossRef] 
12. Krahmer, D.M.; Polvorosa, R.; López de Lacalle, L.N.; Alonso-Pinillos, U.; Abate, G.; Riu, F. Alternatives for specimen manufacturing in tensile testing of steel plates. Exp. Tech. 2016, 40, 1555-1565. [CrossRef]

13. Kim, J.C.; Cheong, S.K.; Noguchi, H. Evolution of residual stress redistribution associated with localized surface microcracking in shot-peened medium-carbon steel during fatigue test. Int. J. Fatigue 2013, 55, 147-157. [CrossRef]

14. Huang, W.; Garbatov, Y.; Guedes Soares, C. Fatigue reliability assessment of a complex welded structure subjected to multiple cracks. Eng. Struct. 2013, 56, 868-879. [CrossRef]

15. Lu, W.; Shi, Y.W.; Lei, Y.P.; Li, X.Y. Effect of electron beam welding on the microstructures and mechanical properties of thick TC4-DT alloy. Mater. Des. 2012, 34, 509-515. [CrossRef]

16. Barreda, J.L.; Santamaría, F.; Azpiroz, X.; Irisarri, A.M.; Varona, J.M. Electron beam welded high thickness Ti6Al4V plates using filler metal of similar and different composition to the base plate. Vacuum 2001, 62, 143-150. [CrossRef]

17. Miki, C.; Fahimuddin, F.; Anami, K. Fatigue performance of butt-welded joints containing various embedded defects. J. Struct. Mech. Earthq. Eng. JSCE 2001, 18, 29-41. [CrossRef]

18. Avilés, R.; Albizuri, J.; Rodríguez, A.; López de Lacalle, L. Influence of low-plasticity ball burnishing on the high-cycle fatigue strength of medium carbon AISI 1045 steel. Int. J. Fatigue 2013, 55, 230-244. [CrossRef]

19. Murakami, Y. Material defects as the basis of fatigue design. Int. J. Fatigue 2012, 41, 2-10. [CrossRef]

20. Wang, B.; De Backer, H.; Chen, A. An XFEM based uncertainty study on crack growth in welded joints with defects. Theor. Appl. Fract. Mech. 2016, 86, 125-142. [CrossRef]

21. Madia, M.; Zerbst, U.; Beier, H.T. A model for the determination of the fatigue life in technical alloys containing large and small defects. Procedia Mater. Sci. 2014, 3, 493-498. [CrossRef]

22. Mikkola, E.; Murakami, Y.; Marquis, G. Equivalent crack approach for fatigue life assessment of welded joints. Eng. Fract. Mech. 2015, 149, 144-155. [CrossRef]

23. Mikheevskiy, S.; Glinka, G.; Cordes, T. Total life approach for fatigue life estimation of welded structures. Procedia Eng. 2015, 101, 177-184. [CrossRef]

24. Zhang, Y.H.; Maddox, S.J. Fatigue life prediction for toe ground welded joints. Int. J. Fatigue 2009, 31, 1124-1136. [CrossRef]

25. Herasymchuk, O.M.; Kononuchenko, O.V.; Bondarchuk, V.I. Fatigue life calculation for titanium alloys considering the influence of microstructure and manufacturing defects. Int. J. Fatigue 2015, 81, 257-264. [CrossRef]

26. Guerchais, R.; Morel, F.; Saintier, N. Effect of defect size and shape on the high-cycle fatigue behavior. Int. J. Fatigue 2017, 100, 530-539. [CrossRef]

27. Cremer, M.; Kolyshkin, A.; Zimmermann, M.; Christ, H.J. Influence of process-related defects on the fatigue behaviour of welded aluminium joints at very high cycles. Adv. Mater. Res. 2014, 891-892, 1476-1481. [CrossRef]

28. Zhao, X.H.; Wang, D.P.; Deng, C.Y.; Liu, Y.; Song, Z.X. The fatigue behaviors of butt welds ground flush in the super-long life regime. Int. J. Fatigue 2012, 36, 1-8. [CrossRef]

29. Tammaswilliams, S.; Withers, P.J.; Todd, I. The influence of porosity on fatigue crack initiation in additively manufactured titanium components. Sci. Rep. 2017, 7, 1-12. [CrossRef]

30. Yang, Z.G.; Li, S.X.; Zhang, J.M.; Zhang, J.F.; Li, G.Y.; Li, Z.B.; Hui, W.J.; Weng, Y.Q. The fatigue behaviors of zero-inclusion and commercial 42CrMo steels in the super-long fatigue life regime. Acta Mater. 2004, 52, 5235-5241. [CrossRef]

31. Serranomunoz, I.; Buffiere, J.Y.; Mokso, R. Location, location \& size: Defects close to surfaces dominate fatigue crack initiation. Sci. Rep. 2017, 7, 45239. [CrossRef]

32. Shimatani, Y.; Shiozawa, K.; Nakada, T.; Yoshimoto, T.; Lu, L. The effect of the residual stresses generated by surface finishing methods on the very high cycle fatigue behavior of matrix HSS. Int. J. Fatigue 2011, 33, 122-131. [CrossRef]

33. Zhu, M.L.; Xuan, F.Z.; Du, Y.N.; Tu, S.T. Very high cycle fatigue behavior of a low strength welded joint at moderate temperature. Int. J. Fatigue 2012, 40, 74-83. [CrossRef]

34. Zhu, M.L.; Xuan, F.Z.; Chen, J. Influence of microstructure and microdefects on long-term fatigue behavior of a Cr-Mo-V steel. Mater. Sci. Eng. A 2012, 546, 90-96. [CrossRef]

35. Zhu, M.; Xuan, F. Fatigue crack initiation potential from defects in terms of local stress analysis. Chin. J. Mech. Eng. 2014, 27, 496-503. [CrossRef] 
36. Balasubramanian, T.S.; Balasubramanian, V.; Manickam, M.M.A. Fatigue crack growth behaviour of gas tungsten arc, electron beam and laser beam welded Ti-6Al-4V alloy. Mater. Des. 2011, 32, 4509-4520. [CrossRef]

37. Kondakov, G.F.; Bantserzh, N.E. Quantitative analysis of defects in arc butt welded joints in titanium alloys. Weld. Int. 1996, 10, 246-248. [CrossRef]

38. Hrabe, N.; Gnäupel-Herold, T.; Quinn, T. Fatigue properties of a titanium alloy (Ti-6Al-4V) fabricated via electron beam melting (EBM): Effects of internal defects and residual stress. Int. J. Fatigue 2017, 94, 202-210. [CrossRef]

39. Murakami, Y.; Nomoto, T.; Ueda, T. Factors influencing the mechanism of superlong fatigue failure in steels. Fatigue Fract. Eng. Mater. Struct. 1999, 22, 581-590. [CrossRef]

40. Mohd, S.; Mutoh, Y.; Otsuka, Y.; Miyashita, Y.; Koike, T.; Suzuki, T. Scatter analysis of fatigue life and pore size data of die-cast AM60B magnesium alloy. Eng. Fail. Anal. 2012, 22, 64-72. [CrossRef]

C 2017 by the authors. Licensee MDPI, Basel, Switzerland. This article is an open access article distributed under the terms and conditions of the Creative Commons Attribution (CC BY) license (http:/ / creativecommons.org/licenses/by/4.0/). 